\title{
Evaluación espacial del comportamiento fenológico de la vegetación mediante imágenes satelitales distrito de chiara-ayacucho 2000-2015
}

\section{Spatial evaluation of the phenological behavior of vegetation using satellite images of the district of chiara-ayacucho 2000-2015}

DOI: $10.46932 / \mathrm{sjjdv2n4-058}$

Received in: May 1st, 2021

Accepted in: Jun 30th, 2021

\author{
Jorge Luis Lozano Rodríguez \\ Universidad Nacional Agraria La Molina, Perú. \\ Correo electrónico: jorgelozano@lamolina.edu.pe \\ Juan Carlos Chang Chang Fun \\ Universidad Nacional Agraria La Molina, Perú. \\ Correo electrónico: jcchang@lamolina.edu.pe \\ Oscar Enrique Tang Cruz \\ Universidad Nacional Agraria La Molina, Perú. \\ Correo electrónico: otang @ lamolina.edu.pe \\ Milagros Rocio Menacho Angeles \\ Universidad Norbert Wiener, Perú. \\ Correo electrónico: milagros.menacho@uwiener.edu.pe \\ Hernán Oscar Cortez Gutiérrez \\ Universidad Nacional del Callao, Perú. \\ Correo electrónico: hocortez@unac.edu.pe \\ Milton Milciades Cortez Gutiérrez \\ Universidad Nacional de Trujillo, Perú. \\ Correo electrónico: mcortezgutierrez@yahoo.es
}

\section{RESUMEN}

La presente investigación se realizó el análisis de las imágenes satelitales MODIS-Terra 250m x 250m de resolución espacial y determinar el comportamiento fenológico de la cobertura vegetal del distrito de Chiara. El objetivo de esta investigación es dar a conocer y demostrar la importancia de la metodología utilizada (imágenes de satélite MOD13Q1) para el análisis multitemporal de la vegetación, mediante el uso del software ENVI, IDL, ArcGIS. En este sentido, se ha logrado describir el comportamiento de la vegetación en el periodo de los dieciséis años, y determinar una variabilidad del área de vegetación en las estaciones anuales de verano, otoño, invierno y primavera y estimar mediante métodos estadísticos la variabilidad del NDVI. Los principales resultados obtenidos son: La variación fenológicos de los ecosistemas, según la estacionalidad climática de las áreas estudiadas. En este sentido, los cambios y variaciones son explicados en base a las características de pixeles de colores. Los resultados obtenidos pueden servir como insumo para mejorar el proceso y clasificación de las imágenes de satélite con el objeto de elaborar mapas temáticos y contribuir a la mejor toma de decisiones en cuanto al uso adecuado de los calendarios agrícolas definidos para cultivos anuales y/o transitorios instalados en dicho distrito. 
Palabras claves: Imágenes de satélite, índices de vegetación NDVI, series de tiempo.

\begin{abstract}
The present research was the analysis of the satellite imagery MODIS-Terra 250m x 250m of spatial resolution and determine the phenological behavior of the vegetation cover of the district of Chiara. The objective of this research is to make known and demonstrate the importance of the methodology used (satellite images MOD13Q1) for multitemporal analysis of vegetation, using the software ENVI, IDL, ArcGIS. In this sense, it has been possible to describe the behavior of vegetation in the sixteen-year period, and to determine a variability of the vegetation area in the annual seasons of summer, autumn, winter and spring and to estimate by means of statistical methods the variability of NDVI. The main results obtained are the phenological variation of the ecosystems, according to the climatic seasonality of the studied areas. In this sense, changes and variations are explained based on the characteristics of colored pixels. The results obtained can serve as input to improve the processing and classification of satellite images in order to produce thematic maps and contribute to better decision making regarding the proper use of the defined agricultural calendars for annual and / or transient crops Installed in that district.
\end{abstract}

Key words: Satellite images, NDVI vegetation indexes, time series.

\title{
1 INTRODUCCIÓN
}

El distrito de Chiara, es uno de los 16 distritos de la Provincia de Huamanga en la Región Ayacucho, ubicado a 3,527 m.s.n.m., con coordenadas geográficas entre los 13²7'03', Latitud Sur y 74²0'33' Longitud Oeste, con un área de extensión territorial de 498,42 km² y una población según INEI-2007 de 6307 hab.

Los estudios realizados de la evaluación espacial del comportamiento fenológico de la vegetación con el uso de imágenes satelitales a través de un parámetro físico conocido como Índice de Vegetación de Diferencia Normalizada (NDVI) Muñoz Aguayo, 2015

son numerosos a nivel internacional, nacional y regional en los últimos años, pero son escasos los trabajos orientados a resolver los problemas locales dejando muchos vacíos y limitaciones; por lo que es necesario e importante tomar en cuenta los resultados del presente trabajo de investigación. Dentro del distrito de Chiara y desde un enfoque de desarrollo agrícola, destaca la vegetación, como uno de los elementos más notorios del medio físico y también más significativo debido a las múltiples relaciones que mantiene con otros elementos del medio que influye en los procesos morfogenéticos, en el modelado del relieve, en los flujos hídricos; y es uno de los elementos más diferenciadores del paisaje como indicador expresivo y nulo de las interacciones que refleja los cambios de las condiciones climáticas creando microclimas locales que constituye recursos económicos y ecológicos. Bajo esta perspectiva el análisis de las imágenes satelitales MODIS-Terra (MOD13Q1) mediante la técnica de Teledetección ha creado una gran expectativa en la caracterización biofísica de la vegetación con la finalidad de describir y estimar la evolución espacio-temporal del Índice de vegetación de diferencia Normalizada y determinar el 
comportamiento fenológico de la cobertura vegetal en el distrito de Chiara. De otro lado, los Sistemas de Información Geográfica SIG, mediante el uso del software ENVI, IDL, ARCGIS y métodos estadísticos como material de trabajo, representan una contribución al desarrollo de la agricultura a beneficio de quienes la trabajan y toman decisiones.

El objetivo de la presente investigación es describir el comportamiento de la vegetación en el periodo de los dieciséis años, y determinar una variabilidad del área de vegetación Bart y Sánchez (2010) en las estaciones anuales de verano, otoño, invierno y primavera.

\section{MATERIAL Y MÉTODOS}

Fueron adquiridas 364 imágenes satelitales MODIS-Terra (MOD13Q1), para el desarrollo del estudio, para el cual se agrupó seis imágenes por estaciones del año (dos por mes). La clasificación de las imágenes para verano comprende los meses de diciembre, enero y febrero, para otoño comprende marzo, abril y mayo, para invierno los meses de junio, julio, agosto y para la estación de primavera los meses de setiembre, octubre y noviembre, desde enero del 2000 a diciembre del 2015. Luego de haber sido apiladas, cortadas y procesadas Watanabe, J. (2010).del promedio temporal, resumidas en imágenes de composición (Chuvieco, 2010), se procedió al cálculo de los índices de vegetación normalizado y diferenciado (NDVI), definido según (Tarpley et al., 1984):

$$
N D V I=\frac{\rho_{I R C}-\rho_{R}}{\rho_{I R C}+\rho_{R}}
$$

En las imágenes de los resultados, observamos colores desde diferentes tonalidades que configuran el paisaje del área de estudio. Desde el color magenta que indica la presencia de elevados valores de NDVI (asociados habitualmente a una vegetación sana o con elevado contenido de humedad), que hace referencia a los sectores donde se desarrollan las actividades agrícolas como cultivos anuales y frutales principalmente. Tonalidades en verde que corresponden a cubiertas vegetales en estado de foliación, floración y fructificación como es el caso de los bosques secos y matorrales en los niveles ralo y muy ralo. Los colores azules (vegetación de colina y sombra), el color celeste que hace referencia a suelos desnudos o sectores con una vegetación arbustiva muy dispersa. Asimismo, el área ocupada por agua, presenta valores negativos y casi nulos (cercanos a -1).

\section{RESULTADOS Y DISCUSIONES}




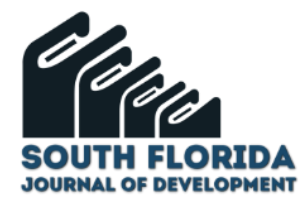

Los resultados obtenidos de la evaluación espacial del comportamiento fenológico de la vegetación mediante imágenes satelitales, cuyo seguimiento de la cobertura vegetal a través del tiempo muestran el resultado estadístico descriptivo de la evolución temporal de la variable dependiente (NDVI) y la variable independiente (comportamiento fenológico) por estaciones y meses del año, durante el periodo 2000 al 2015.

\subsection{RESULTADOS DE LAS IMÁGENES POR BANDAS.}

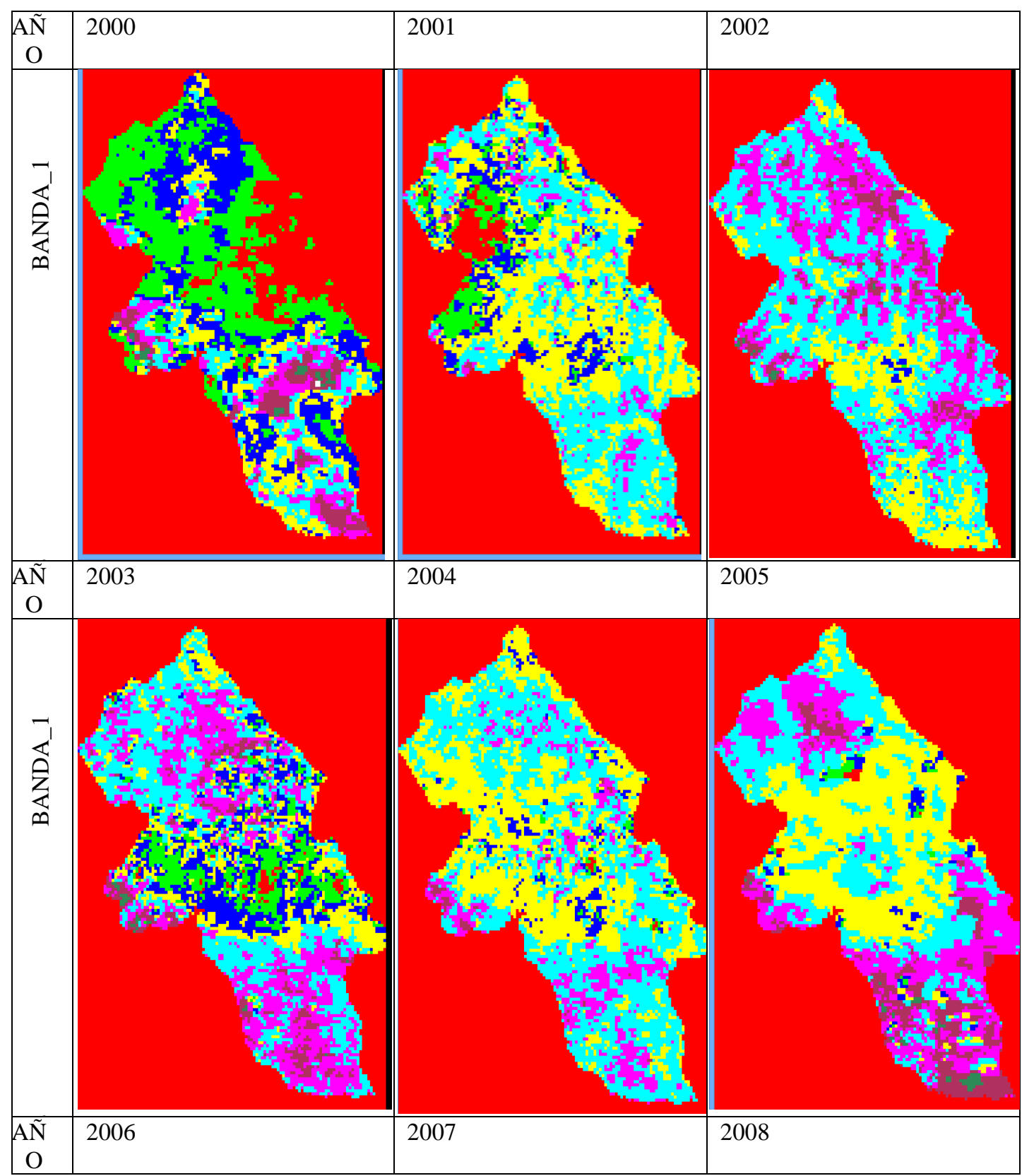



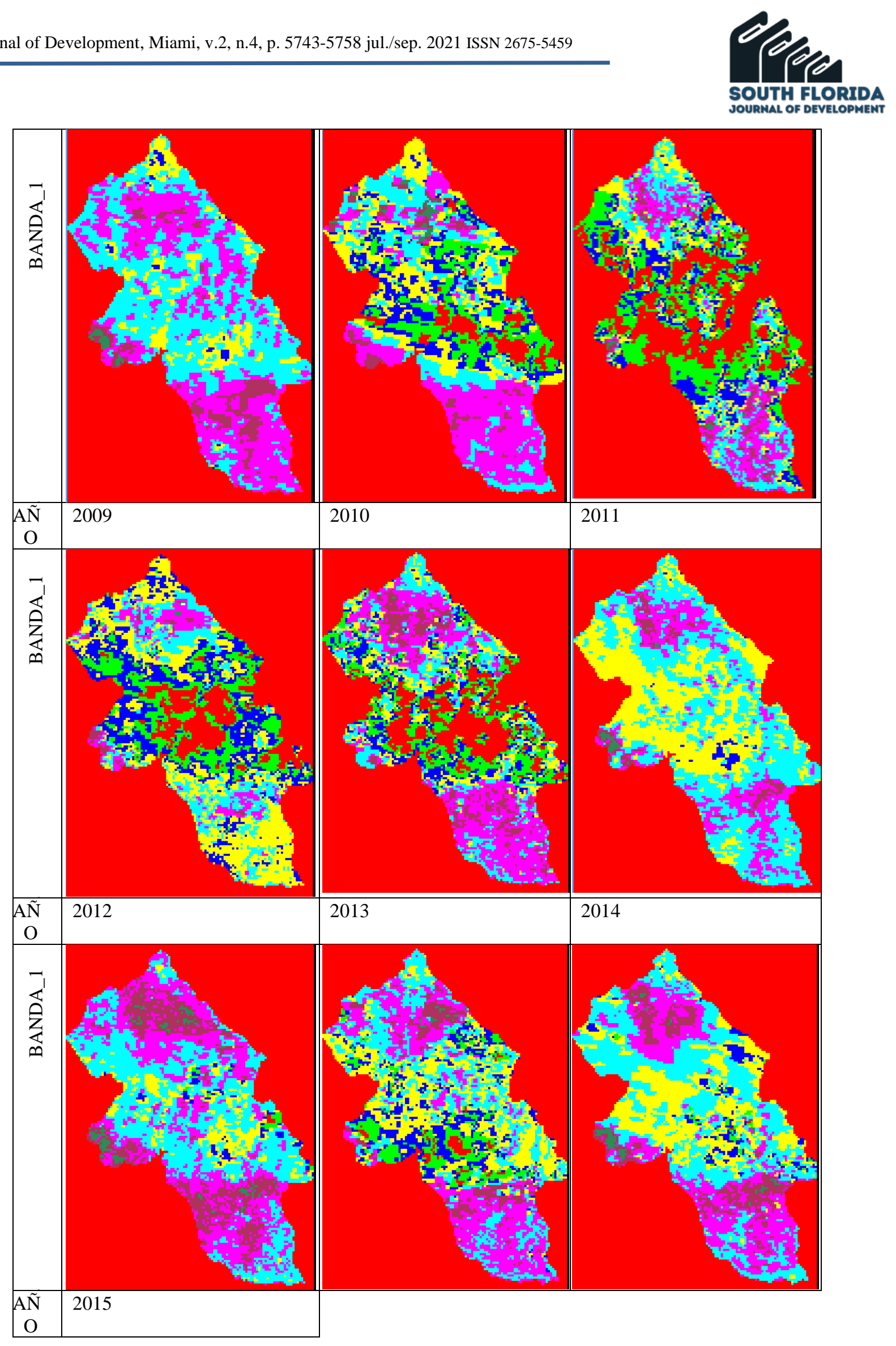


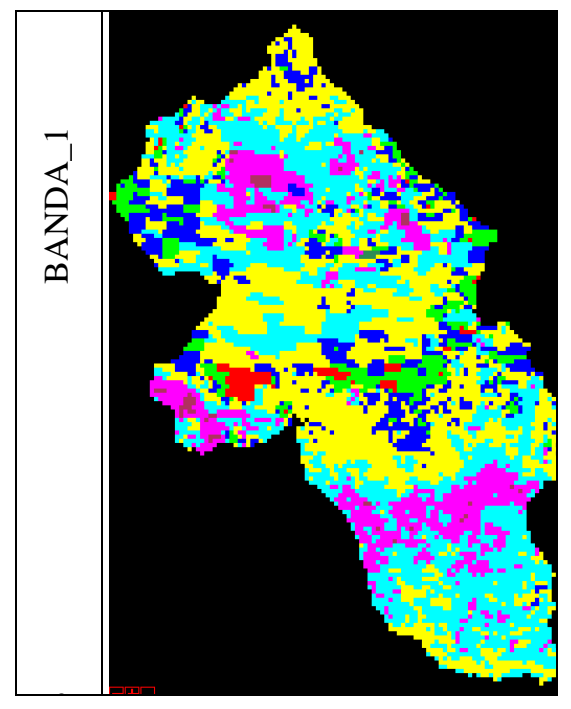

3.2 RESULTADOS DE LAS IMÁGENES SATELITALES POR ESTACIONES DEL AÑO

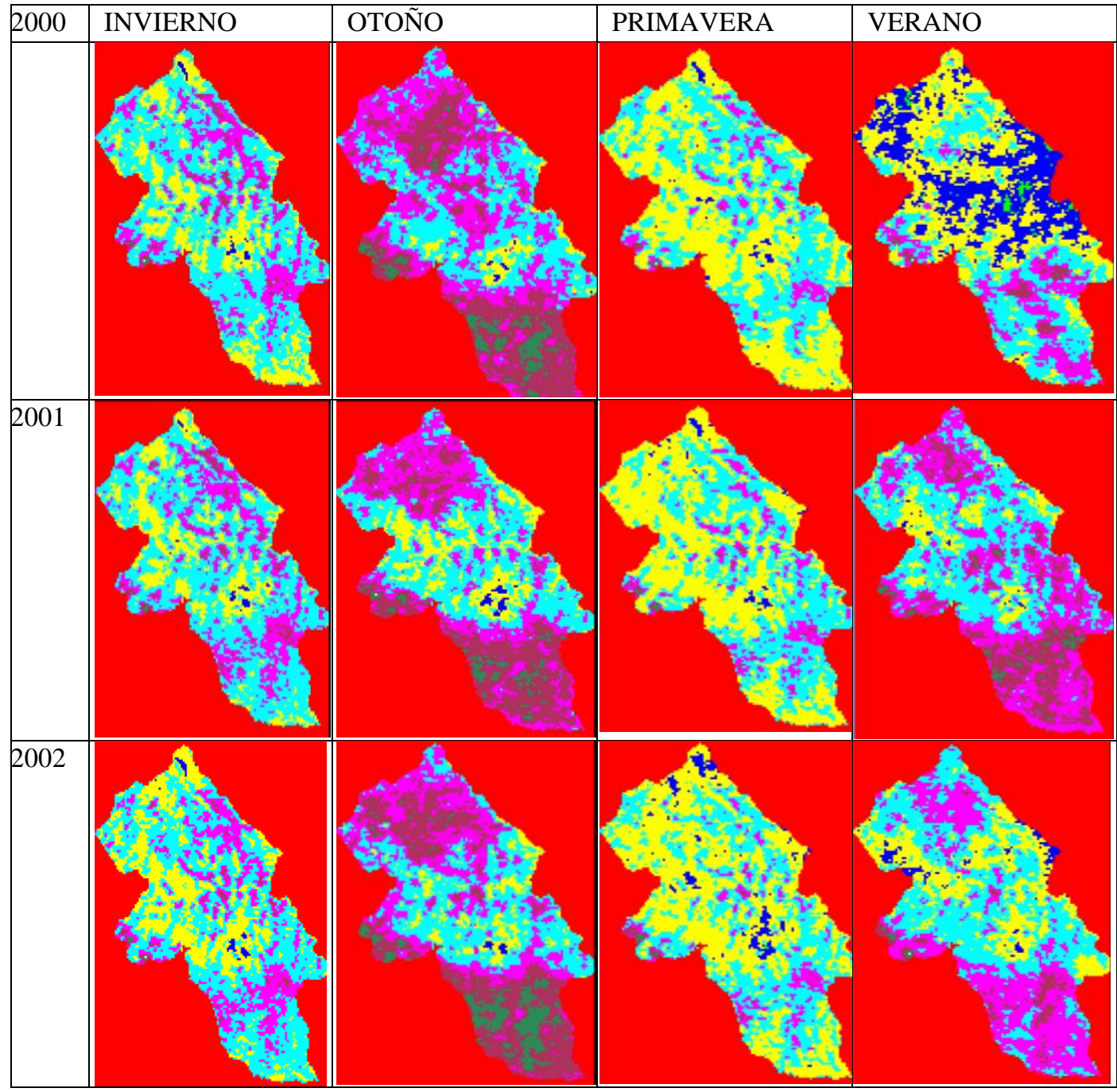



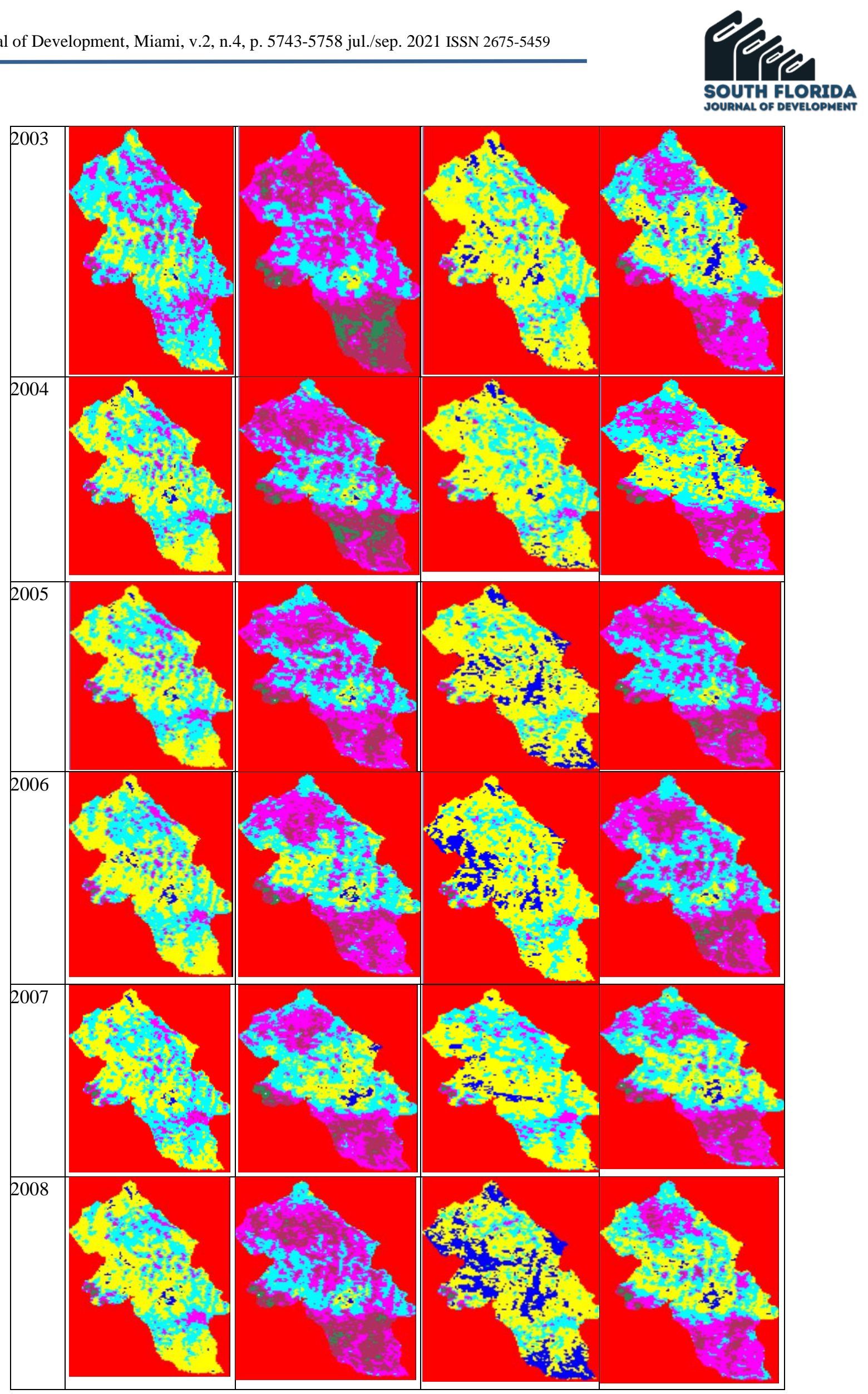

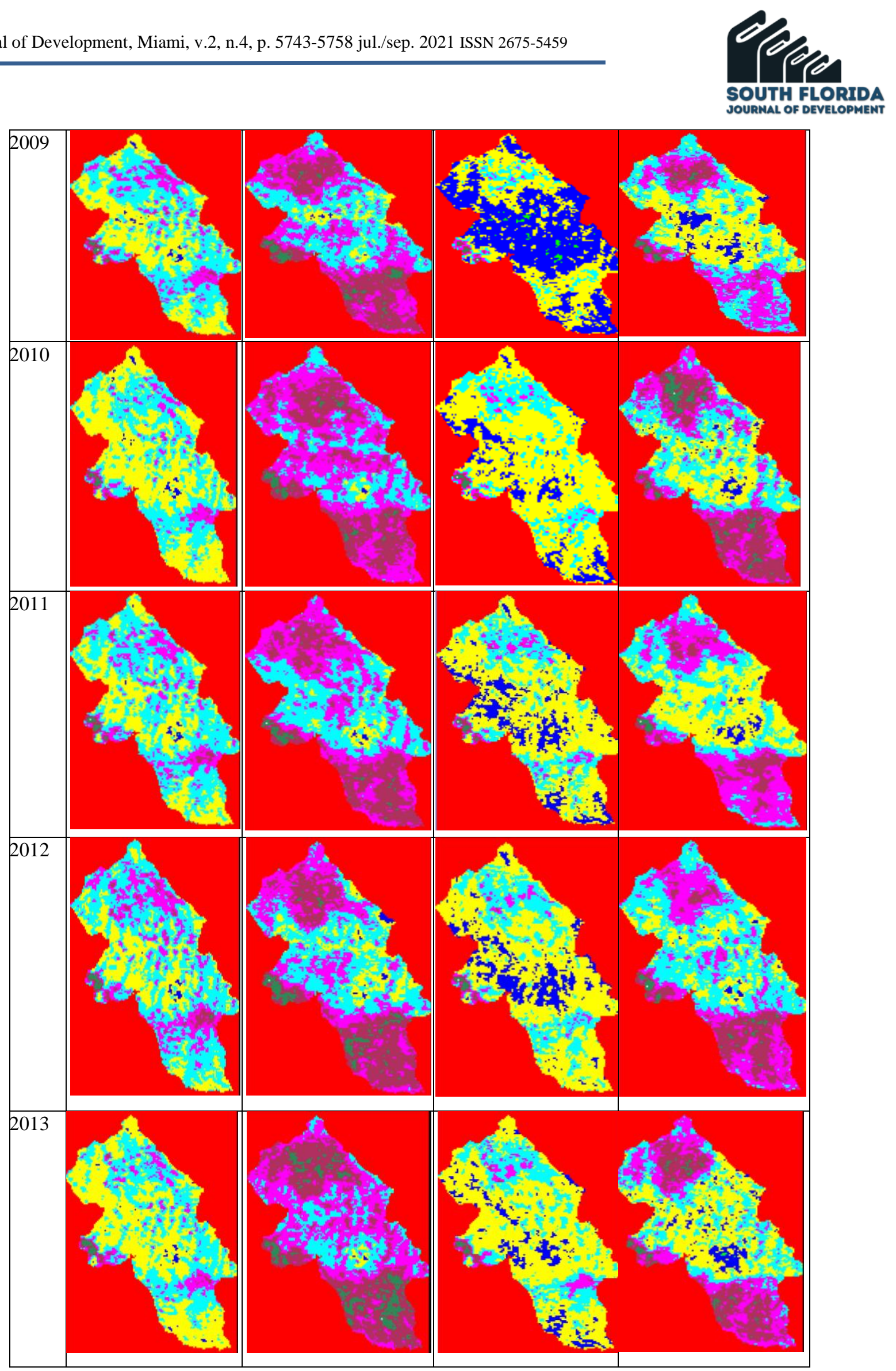


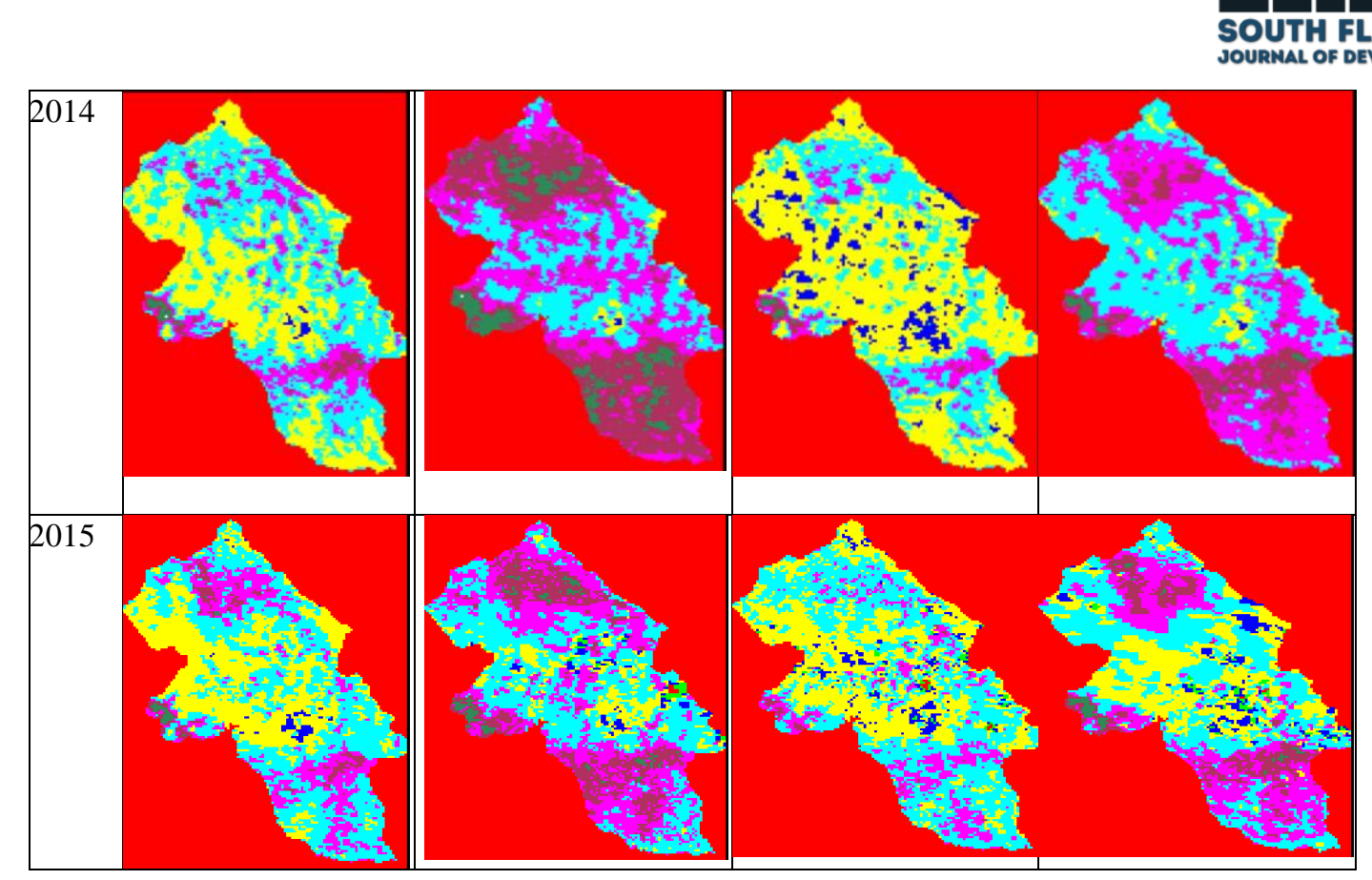

3.3 EVOLUCIÓN TEMPORAL DEL NDVI EN EL PERIODO 2000-2015

Tabla 4.1 Datos del NDVI por meses del periodo 2000-2015

\begin{tabular}{|c|c|c|c|c|c|c|}
\hline MESES & NDVI-2000 & NDVI-2003 & NDVI-2006 & NDVI-2009 & NDVI-2012 & NDVI-2015 \\
\hline & & 0.45255844 & 0.50422503 & 0.32845721 & 0.53060284 & 0.22649956 \\
\hline & & 0.53044585 & 0.51631084 & 0.44021368 & 0.45237939 & 0.20790457 \\
\hline & & 0.40978924 & 0.6467943 & 0.53661705 & 0.49704706 & 0.24583055 \\
\hline feb-02 & 0.26471927 & 0.51534345 & 0.43097065 & 0.33157391 & 0.59957792 & 0.3078854 \\
\hline mar-01 & 0.36938126 & 0.57899 & 0.46246476 & 0.647196 & 0.49788773 & 0.20825563 \\
\hline mar-02 & 0.52400282 & 0.42217036 & 0.37187184 & 0.54277492 & 0.50141996 & 0.27530751 \\
\hline abr-01 & 0.5665532 & 0.57503288 & 0.59829828 & 0.49932587 & 0.52893127 & 0.26236771 \\
\hline abr-02 & 0.55728077 & 0.56154809 & 0.56720905 & 0.56772851 & 0.56816862 & 0.26907881 \\
\hline may-01 & 0.51751549 & 0.51416636 & 0.54208649 & 0.51169221 & 0.54554826 & 0.25622522 \\
\hline may-02 & 0.48670252 & 0.48854106 & 0.45399847 & 0.4759223 & 0.510685 & 0.23634537 \\
\hline jun-01 & 0.4222255 & 0.42984392 & 0.39600672 & 0.43492658 & 0.43872496 & 0.22249609 \\
\hline jun-02 & 0.39354387 & 0.37904967 & 0.36213402 & 0.38187127 & 0.4059606 & 0.20377189 \\
\hline jul-01 & 0.37338791 & 0.35684523 & 0.33354009 & 0.34761506 & 0.37706464 & 0.18075907 \\
\hline jul-02 & 0.3450728 & 0.32151087 & 0.3096385 & 0.34245674 & 0.345986 & 0.16575365 \\
\hline ago-01 & 0.32692709 & 0.32981899 & 0.3048894 & 0.32933869 & 0.32687155 & 0.15768777 \\
\hline ago-02 & 0.31631931 & 0.33263177 & 0.30849079 & 0.30559366 & 0.31883641 & 0.16311265 \\
\hline set-01 & 0.31857196 & 0.32210578 & 0.30010755 & 0.31151219 & 0.30705012 & 0.16394165 \\
\hline set-02 & 0.29949352 & 0.32022602 & 0.30535176 & 0.29754808 & 0.31408825 & 0.16407912 \\
\hline oct-01 & 0.34745486 & 0.3169125 & 0.31399897 & 0.27661338 & 0.30706091 & 0.14730435 \\
\hline 0ct-02 & 0.37252552 & 0.32650837 & 0.31675456 & 0.30242102 & 0.38045943 & 0.15480479 \\
\hline nov-01 & 0.33382178 & 0.32339125 & 0.46499362 & 0.18962529 & 0.3838845 & 0.18219787 \\
\hline dic-01 & 0.36619961 & 0.32592895 & 0.45004372 & 0.45034931 & 0.41166433 & 0.1930898 \\
\hline dic-02 & 0.30193061 & 0.39273919 & 0.40788872 & 0.4967627 & 0.41334216 & 0.21618482 \\
\hline MESES & NDVI-2001 & NDVI-2004 & NDVI-2007 & NDVI-2010 & NDVI-2013 & \\
\hline
\end{tabular}




\begin{tabular}{|c|c|c|c|c|c|}
\hline ene-01 & 0.41639763 & 0.50984056 & 0.45957953 & 0.42132891 & 0.47391076 \\
\hline ene-02 & 0.42666985 & 0.49976813 & 0.52967154 & 0.57182719 & 0.50601811 \\
\hline feb-01 & 0.35374757 & 0.44623876 & 0.63627104 & 0.56769754 & 0.46672963 \\
\hline feb-02 & 0.54759973 & 0.47230505 & 0.54810134 & 0.40623023 & 0.37442585 \\
\hline mar-01 & 0.4295437 & 0.47861608 & 0.41446045 & 0.5402015 & 0.50323936 \\
\hline mar-02 & 0.41574025 & 0.53378695 & 0.38448164 & 0.5472685 & 0.59708059 \\
\hline abr-01 & 0.57100751 & 0.58108258 & 0.52653437 & 0.65194152 & 0.59700696 \\
\hline abr-02 & 0.54400012 & 0.55524289 & 0.52268013 & 0.56999361 & 0.55044856 \\
\hline may-01 & 0.50642718 & 0.52244556 & 0.56238693 & 0.52716961 & 0.49611714 \\
\hline may-02 & 0.48925474 & 0.4516539 & 0.4856684 & 0.49787678 & 0.46853837 \\
\hline jun-01 & 0.45291687 & 0.37822624 & 0.43724191 & 0.42904736 & 0.43935378 \\
\hline jun-02 & 0.33963397 & 0.36446087 & 0.38563645 & 0.37405632 & 0.38797083 \\
\hline jul-01 & 0.36000403 & 0.34096435 & 0.364549 & 0.34253504 & 0.37702123 \\
\hline jul-02 & 0.35354824 & 0.3165047 & 0.33371445 & 0.3149184 & 0.352808 \\
\hline ago-01 & 0.3209357 & 0.30478755 & 0.31709085 & 0.30260927 & 0.33769231 \\
\hline ago-02 & 0.30243205 & 0.29566859 & 0.29586418 & 0.29549693 & 0.33001584 \\
\hline set-01 & 0.33058788 & 0.29392975 & 0.30895863 & 0.31187785 & 0.30923857 \\
\hline set-02 & 0.31507706 & 0.34535961 & 0.30989446 & 0.31578248 & 0.31180068 \\
\hline oct-01 & 0.35605559 & 0.35525884 & 0.27813773 & 0.32297444 & 0.34051854 \\
\hline nov-01 & 0.35127032 & 0.37945981 & 0.32805441 & 0.32996049 & 0.37187769 \\
\hline nov-02 & 0.37346457 & 0.37325255 & 0.34613584 & 0.32720454 & 0.39356684 \\
\hline dic-01 & 0.40378674 & 0.36434993 & 0.33955324 & 0.34875711 & 0.44839405 \\
\hline dic-02 & 0.48544683 & 0.44968567 & 0.33533515 & 0.45781198 & \\
\hline MESES & NDVI-2002 & NDVI-2005 & NDVI-2008 & NDVI-2011 & NDVI-2014 \\
\hline 2002-ene-01 & 0.44478659 & 0.47006967 & 0.2715893 & 0.45782072 & 0.49577677 \\
\hline ene-02 & 0.45277477 & 0.52104211 & 0.6053587 & 0.53356145 & 0.58518848 \\
\hline feb-01 & 0.32820865 & 0.54337136 & 0.51565915 & 0.43903115 & 0.55305834 \\
\hline feb-02 & 0.52712855 & 0.55427512 & 0.49522972 & 0.57549186 & 0.59042039 \\
\hline mar-01 & 0.49947806 & 0.63535662 & 0.59134765 & 0.5808874 & 0.57086483 \\
\hline mar-02 & 0.49164349 & 0.45388405 & 0.58533199 & 0.27967081 & 0.6120334 \\
\hline abr-01 & 0.560774 & 0.5711543 & 0.61729993 & 0.61293555 & 0.55649537 \\
\hline abr-02 & 0.58458271 & 0.54300587 & 0.56578914 & 0.58462134 & 0.56114798 \\
\hline may-01 & 0.53328043 & 0.47869511 & 0.47694305 & 0.53983762 & 0.56038662 \\
\hline may-02 & 0.50848793 & 0.41270186 & 0.43651839 & 0.4996297 & 0.50360957 \\
\hline jun-01 & 0.44410272 & 0.37776895 & 0.39399193 & 0.45596066 & 0.43794776 \\
\hline jun-02 & 0.41053453 & 0.34526359 & 0.36491074 & 0.40563961 & 0.40123284 \\
\hline jul-01 & 0.38496782 & 0.31788774 & 0.33934846 & 0.38323275 & 0.3862083 \\
\hline jul-02 & 0.3715242 & 0.31589396 & 0.32824161 & 0.35059619 & 0.36058839 \\
\hline ago-01 & 0.34782953 & 0.2963871 & 0.30287097 & 0.31385603 & 0.34302156 \\
\hline ago-02 & 0.3529871 & 0.29628179 & 0.27785865 & 0.31832601 & 0.32354899 \\
\hline set-01 & 0.35858623 & 0.2974588 & 0.29266894 & 0.30634475 & 0.34005914 \\
\hline set-02 & 0.38757816 & 0.33366422 & 0.28210251 & 0.32800016 & 0.32069318 \\
\hline oct-01 & 0.36245469 & 0.34471076 & 0.30807083 & 0.34507426 & 0.39648429 \\
\hline nov-01 & 0.40309379 & 0.33660972 & 0.31273613 & 0.36935822 & 0.38161066 \\
\hline nov-02 & 0.36388484 & 0.34971136 & 0.3177089 & 0.38538209 & 0.43578506 \\
\hline
\end{tabular}




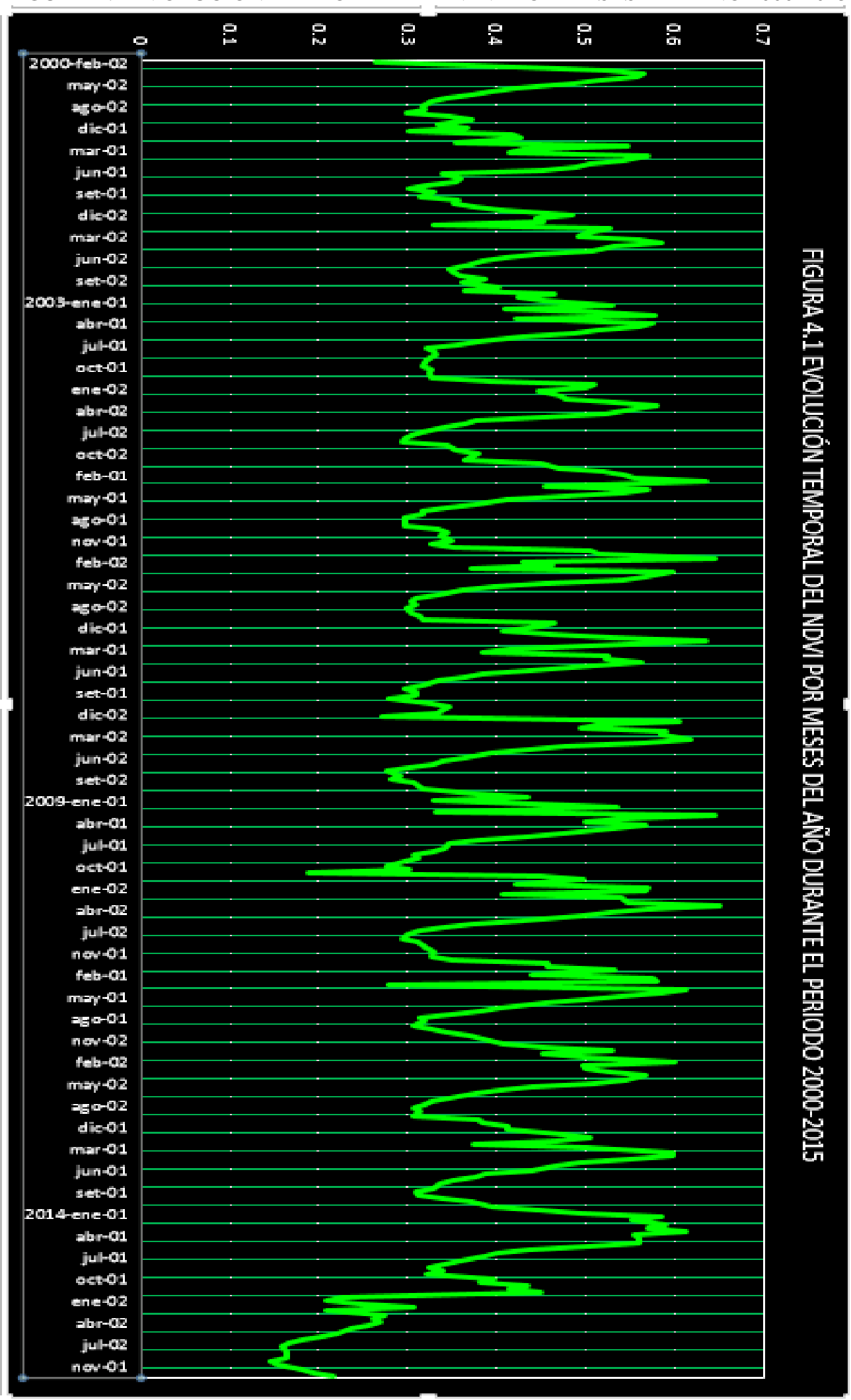




\subsection{MÍNIMOS Y MÁXIMOS NDVI 2000-2015}

FIGURA 4.2 COMPORTAMIENTO DEL NDVI DEL 2000 AL 2015 CHIARA-AYACUCHO

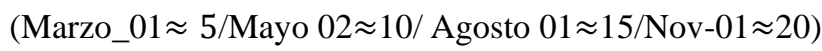

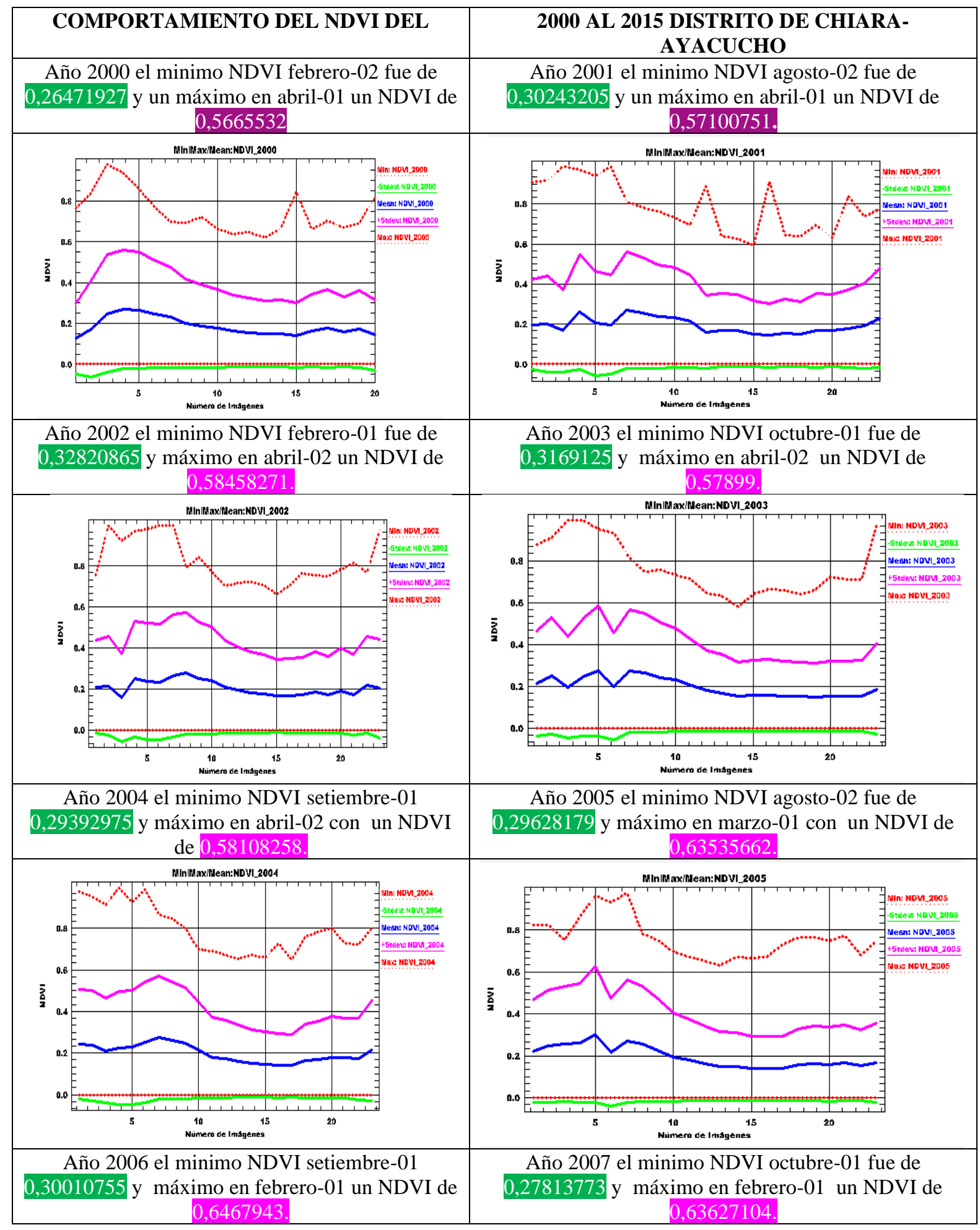




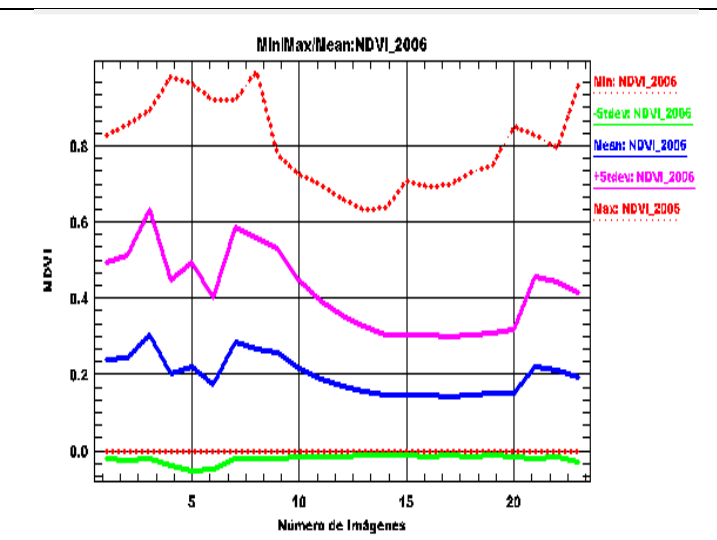

Año 2008 el minimo NDVI enero-01 fue de 0,2715893 y máximo abril-01 un NDVI de $0,61729993$.

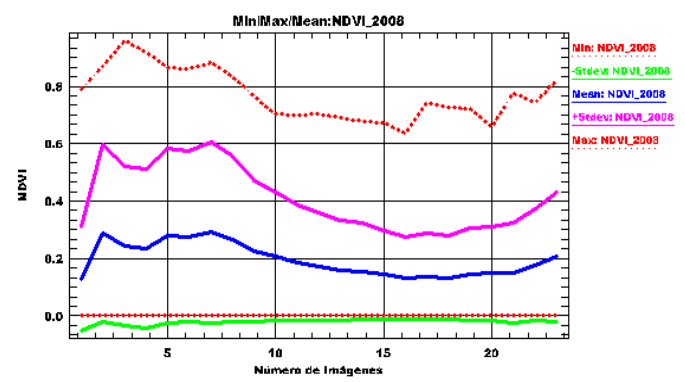

Año 2010 el minimo NDVI agosto-02 fue de 0,29549693 y máximo abril-01 un NDVI de 0,65194152 .

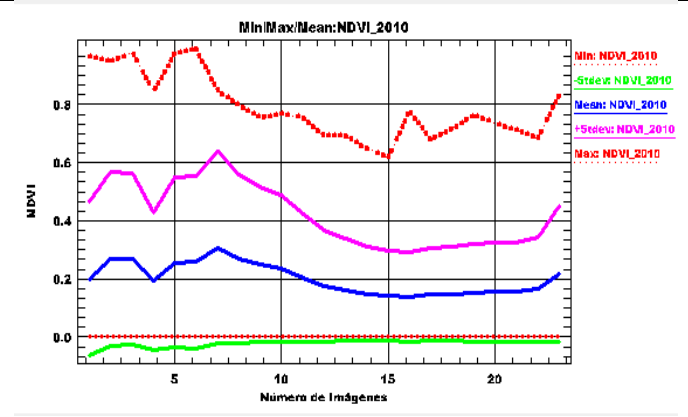

Año 2012 el minimo NDVI setiembre-01 fue 0,30705012 y máximo febrero-02 un NDVI de 0,59957792 .

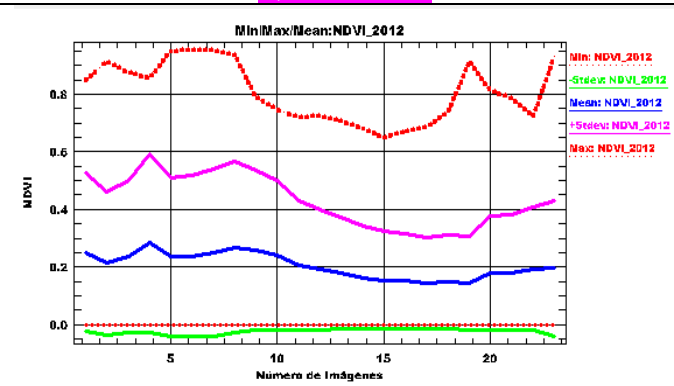

Año 2014 el minimo NDVI setiembre-02 fue 0,32069328 y máximo marzo-02 un NDVI de 0,6120334 .

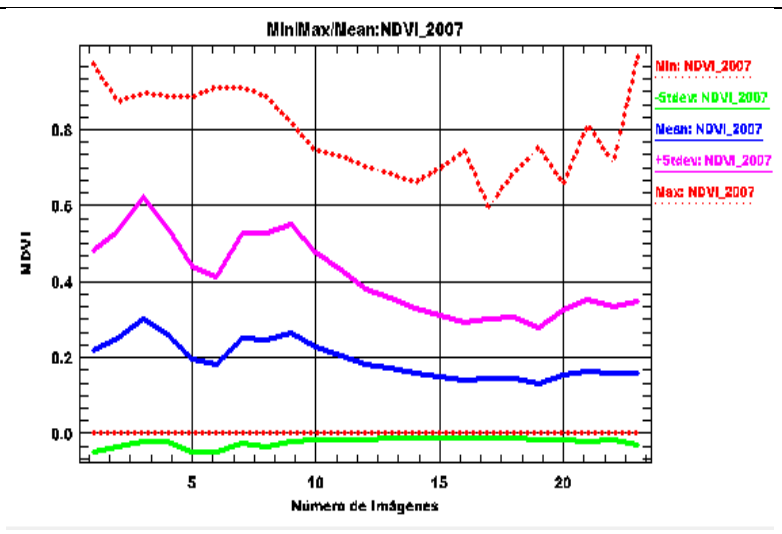

Año 2009 el minimo NDVI noviembre-02 fue de 0,18962529 y máximo marzo-01 un NDVI de $0,647196$.

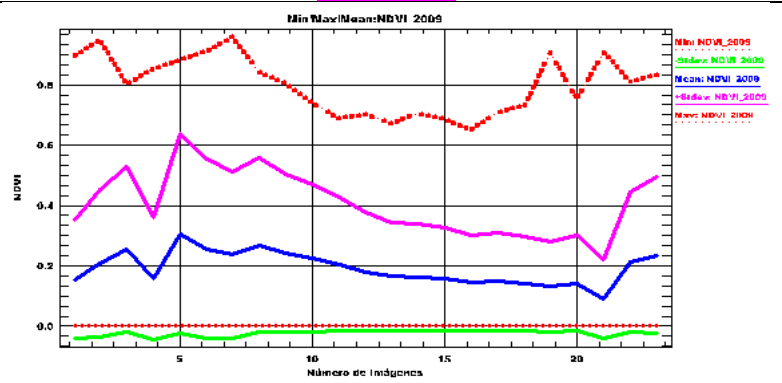

Año 2011 el minimo NDVI marzo-02 fue de 0,27967081 y máximo abril-01 un NDVI de 0,61293555 .

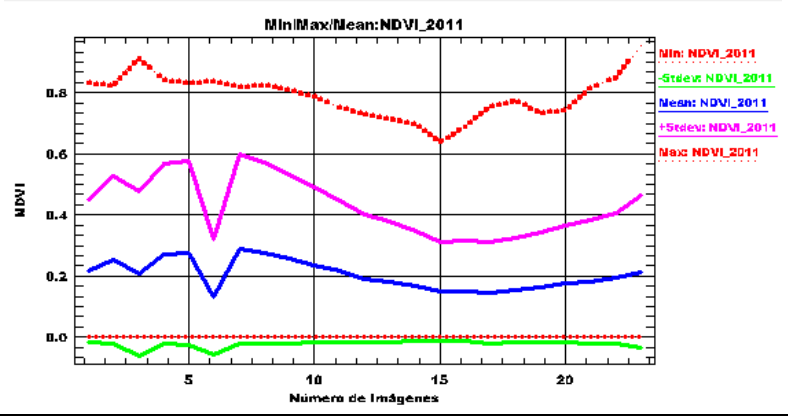

Año 2013 el minimo NDVI setiembre-01 fue 0,30923857 y máximo marzo-02 un NDVI de 0,59708059 .

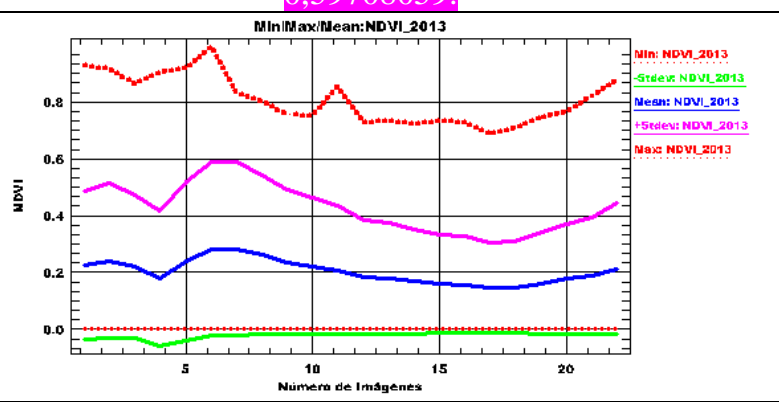

Año 2015 el minimo NDVI octubre-01 fue de 0,14730435 y máximo febrero-02 un NDVI de 0,3078854 . 


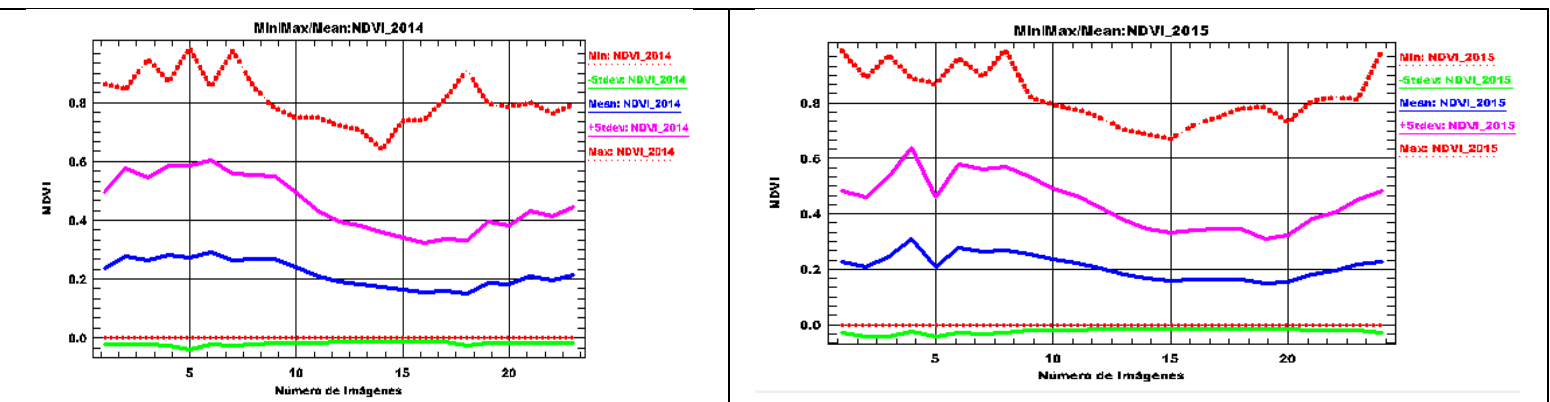

\section{DISCUSIÓN DE RESULTADOS}

1. Los resultados mostrados evidencias efectivamente que existió una diferencia significativa por meses del año y por estación del año en el comportamiento fenológico de la vegetación no encontrando información a corroborar en dicho estudio, solo tenemos información del ZEE-2012 del gobierno regional de Ayacucho a nivel de provincias y no así a nivel micro (distritos).

2. En 4.1 se observa los resultados obtenidos de las imágenes satelitales en la banda_1 y en el 4.2 los resultados de las imágenes por estaciones del año desde 2000 hasta el 2015, según la paleta de colores se observa los diferentes tipos de evaluación espacial del comportamiento fenológico de la vegetación.

3. En la tabla 4.1 y figura 4.1 se muestran los valores del NDVI por meses del año donde se observa una tendencia de crecimiento positivo llegando a un NDVI de valor más alto de 0.647196 en el mes de marzo del 2009 y mínimo de 0.14730435 en el mes de octubre del 2015. Teniendo en cuenta que se utilizó la ecuación 3.1 y el NDVI de dos imágenes al mes. Los meses que no hay lluvias, el NDVI es menor (escasa vegetación mes de octubre) y meses después de las lluvias el NDVI es mayor (incremento de la vegetación mes de marzo).

4. Los resultados en el 4.4, dan respuesta a nuestras hipótesis planteadas pues concuerdan con las conclusiones experimentales previamente establecidas.

\section{CONCLUSIONES}

1. Se logró describir la evaluación espacial del comportamiento fenológico de la vegetación mediante imágenes satelitales distrito de Chiara-Ayacucho 2000-2015" de acuerdo al Índice de Vegetación de Diferencia Normalizada con las 341 imágenes (MOD13Q1) según estaciones del año y la cobertura vegetal de suelos en series de tiempo, como muestra los resultados de las Tablas 4.2 y Figuras 4.1, alcanzando así los objetivos específicos propuestos.

2. Se logró evaluar el comportamiento fenológico de la vegetación mediante imágenes satelitales mediante el uso del Índice de Vegetación de Diferencia Normalizada en series de tiempo, durante el 
periodo 2000 al 2015 con información generada por las imágenes satelitales MODIS Terra del distrito de Chiara, como muestra la Tabla 4.1 y Figura 4.1, logrando así el objetivo general planteado.

3. Se determinó un aumento del NDVI y las áreas de cobertura vegetal, lo que causó una disminución en áreas de zonas de suelo desnudo, lo cual es satisfactorio debido a que indica la mejora en el comportamiento fenológico de la vegetación en el distrito de Chiara.

4. Los resultados de las actividades propuestas en el plan anual de manejo de áreas de cultivo por las entidades pertenecientes al Gobierno Regional de Ayacucho (irrigación por aguas del proyecto especial rio Cachi), arrojaron un impacto positivo de la cobertura vegetal.

\section{AGRADECIMIENTO}

A la Universidad Nacional de San Cristóbal de Huamanga por hacer posible el desarrollo del presente trabajo de investigación. Igualmente, agradecemos al Lic. Wilmer Moncada Sosa, por sus alcances teóricos relacionados al tema. 


\section{REFERENCIAS BIBLIOGRAFÍCAS}

- CARVACHO BART, L. y SÁNCHEZ MARTÍNEZ, M. (2010). "Comparación de índices de vegetación a partir de imágenes MODIS en la región del Libertador Bernardo O’Higgins, Chile; en el período 2001-2005”. En: Ojeda, J., Pita, M.F. y Vallejo, I. (Eds.) Tecnologías de la Información Geográfica: La Información Geográfica al servicio de los ciudadanos. Secretariado de Publicaciones de la Universidad de Sevilla, España.

- CHUVIECO, E y HUETE, A.(2010). Fundamentals of Satellite Remote Sensing. [Libro]: Taylor y Fransis group, [27/04/2016]. New York.

Disponible en: https://www.agroclimatico.minagri.gob.cl/.../2015/.../Indices-de-vegetación-PedroMuñoz.

- GILABERT, M.A., J. GONZALES Y J. GARCÍA. (1997). Acerca de los índices de vegetación Revista de Teledetección, 8:35-45, España.

- MUÑOZ AGUAYO, P. (2015). Índice de Vegetación Diferencial Normalizado. [Tesis maestría]. Departamento Provincial de Aguas de Argentina.

- TARPLEY. J.D. (1984). noaa/nesdis/satellite aplicationes, laboratory (United States) Published in SPIE Proceedings Vol. 0481: Arlington-EEUU.

- WATANABE, J. (2010). Manejo del ENVI 4,8 [Monografía en internet]. Consultado 09 de setiembre 2016, http://www.monografias. Com/trabajos82/manejo-envi/manejo-envi4.8.shtml.

- ZEE. GOBIERNO REGIONAL DE AYACUCHO. (2012). Documento: Memoria Descriptiva de Cobertura Vegetal y Uso Actual-ZEE del departamento Ayacucho-Perú. 